\title{
Impact of colors on advertisement and packaging on buying behavior
}

\author{
Tabinda Seher ${ }^{\mathrm{a}}$, Muhammad Arshad $^{\mathrm{a}}{ }^{*}$, Shaheer Ellahi ${ }^{\mathrm{b}}$ and Maryam Shahid ${ }^{\mathrm{c}}$
}

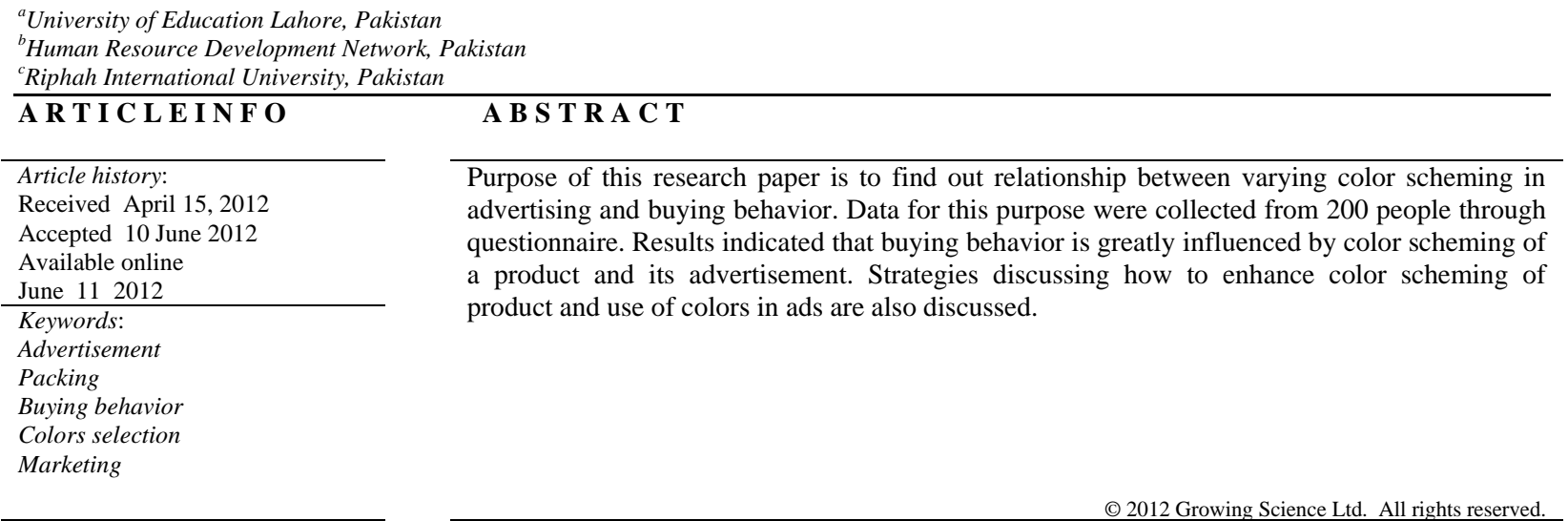

\section{Introduction}

Research on "Color scheming" is gaining increased awareness and popularity among the number of marketing researchers. The main reason behind this is that human brain receives signals faster through eyes rather than ears. Young (1802) supported this by showing the impact of luminous body and its colored particles, when they get into the eyes of a human being. It's obvious that one feels the visuals readily and uses other senses afterwards. Palmeri et al. (2002) explained that the visual appearance of objects first moves to neural activity within diverse brain areas and helps in the product acknowledgment and detection. By using different methods, we can increase the quality of visuals used in ads and packaging. Now a days we see that product with an effective color scheming gains success in consumers while many products fail due to poor color scheming. Brightness of colors and their saturation levels have different impacts according to the saturation level. For example, light yellow shows cheerfulness while dark yellow does not. Similarly, green and red have different impacts according to their saturation (Andare \& Egan, 1974). Similarly, Friedmann and Zimmer (1988) emphasized on the importance of psychological meaning in advertising and its importance for

\footnotetext{
* Corresponding author.

E-mail addresses: arshad8993@hotmail.com (M. Arshad) 
further researches. Purves et al. (2001) explained that brightness of colors has different impacts on human minds and in return they respond accordingly. Thus showing the fact that colors mostly changes the human responsive behavior.

"Buying Behaviors" are the decision processes and acts of people involved in buying and using products. For understanding buying behavior, we need to understand why consumers make the purchases that they make, what factors control consumer purchases, and the altering factors in our society. A firm needs to examine buying behavior because buyer's reactions to a firms marketing strategy has a great impact on the firm's accomplishment. It stresses that a firm should generate such strategies, which satisfies customers and therefore need to evaluate that what, where, when and how consumers buy. Marketers can better forecast how consumers will respond to marketing strategies. Consumer's behavior depends on many factors. Brown (1950) said that majority of buyers were mostly influenced by a number of factors, including prestige, advertising, and satisfactory familiarity in use, but in most occasions the authentic liking for a fastidious chief brand seemed pathetic. However, one significant factor is the psychological impact on consumer's mind of a particular product. Sewall (1978) said that in market segments a lot of people were observed, having different intentions to purchase similar product. Color is one of the basic things, which have a psychological impact on consumers mind and in result on his buying behavior.

Relationship between colors and buying behavior is very profound. Product's packaging and color have direct and first impact on consumers psyche. Therefore, it is important to do research on this topic to distinguish which colors mostly impact positively and which impact negatively on consumer's choice and consequently on buying behavior. The conclusion of Brody et al. (1981) research shows that television advertisements have great impact on children consumerism. So the children do not know about the substantial components or quality of a product. They are only fascinated towards the colors of the product. Therefore, if an advertisement has good color scheme it will attract a lot of children and consequently buyers for the company. The good commercials attract children's attention and hence motivate their parents for buying the product (Brody et al., 1981). Earlier studies show that roughly $80 \%$ of the hiring decisions are based on exterior factors, and that $65 \%$ of that involves clothing color. Brown and green seem to arouse confidence, and some designers use this information for intake interviews. In addition, black and deep blue colors imply authority. All this shows the importance of colors in human perception and hence decisions.

In Pakistan, creative and innovative ads are gaining fame. Different ads like ads of cellular companies are much admired now a day and it's due to their unique designing and color scheming. While if we observe the literature on this topic related to Pakistan we see no significant research has been done on this area, even considering it as a basic element. Therefore, it is very essential to do research on this topic. Our research will provide an opportunity of enhancing the competitive advantage, the benefit or value which their services provide, their professional image, and the niche they occupy in the marketplace. A motive is an internal energizing force that orients a person's activities toward satisfying a need or achieving a goal this may include a person's favorite color. Actions are effected by a set of motives and if marketers can identify appropriate motives and the best persuasive colors for their target consumers then they can develop a better marketing mix.

\section{Literature review}

Buying behavior is a process in which individuals search for, select, purchase, use, and dispose of goods and services, in satisfaction of their needs and wants. Market research and consumer behavior research will gain popularity and advancement if importance of advertising is understood in these processes (Padberg \& Westgren, 1979). Buying behavior is all about the perception of different products in the minds of target consumers. Sewall in (1978) predicted in his work that buying behavior is based on how consumers perceive. It could be the way media show a product and the way consumer perceives it. Whenever designing a new product it should be considered in the mind that it 
is being designed for the end users or the customers, so that it should be designed according to their needs and wants .

To make their programming more effective and understandable the program makers need to focus on human emotions and their interests thus showing that the message could be made more effective if it caters the human requirements (Leurdijk, 2006). Products now days are being promoted through advertising. In addition, children are the ones who are being convinced the most through attractive advertisements; thus resulting in growing buying behaviors towards products (Moore \& Lutz, 2000). Therefore, advertising becomes another important factor behind consumer's choices. Supporting the same argument, Hempel (1974) forecasted that family buying decisions could not be calculated by only considering the husband and wife, there are many other factors involved like children. Another type of consumer buying behavior is the one marked by an absence of brand loyalty. Buying behavior is the decision process and actions of people involved in buying and using products. The concept that females do shopping as they desire i.e. their perception and own likeness towards a product would diversify their shopping criteria was derived by Azevedo et al. (2008). Buying behavior is one in which a consumer buys the same brand again and again. This greatly depends on the cultural values norms and religion. Kacen and Lee (2002) gave an idea that cultural norms and values have a strong impact on consumer's behavior against any product. The innovation of new product buying is maximum and most exciting for initial purchases that the youth excessively make in these product classes (Oropesa, 1995).

Product could be made successful and reach the market competency, than the packaging needs to be so eye-catching that it attracts customers in first sight. This could only be done if packaging is done in attractive and appealing colors as Gardner (1985) illustrated in his findings that consumer behaviors depend on his mood states and secondly he told that the advertisements have a great impact on consumer moods. Planning of the environment, considering factors as organization's task environment and market power, would give way more clear-cut descriptions of discrepancies in buying behavior (Gronhaug, 1976). If we look it from another perspective, products perform the same functions but still some are liked more than others are. All soaps perform the same function of cleaning but the ones with attractive packaging are liked more. O'Guinn and Faber (1989) originated the concept of two types of buyers in their research, general and compulsive buyers. He said that general buyers were possessive while compulsive buyers were not even compulsive buyers did exhibit more jealousy and miserliness. Habit buying implies the absence of dissatisfaction with a brand rather than positive loyalty to it and is usually associated with the purchase of low involvement products. Timmermans et al. (1984) emphasized the importance of the topic for further researches to uncover the nature of decision-making processes in the background of shopping behavior. Buying is associated with advertising and buying may change the phenomenon of advertising (Stern, 1962).

Advertising is one of the most important tools being used to motivate the consumers for not only the product trail but to purchase it again and again. Advertisements are some of the major factors for market assessment, therefore, considerations need to be taken as to how to manage advertising (Conchar et al., 2005). The advertisement designer, while designing his advertisement should keep in mind the nature and theme of product. Even the most important factors, still advertising and branding are not extensively used tools (Mehren, 1948). A lot of studies as mentioned before discussed the importance of advertising and its relationship with buying behaviors. Advertisement directly effects buying (Lotz, 2007). Major findings of Gorn (1982) showed that advertising controls product choice and thus creating a positive attitude towards the advertised products. In early days, traditional ways of communicating commonly seen were radio; black and white television and printing press, as the times have changed new and modernized technologies have been established to deliver same messages. Talking about the tourism, campaigns could run more successfully if advertisement is done well before time (Bagozzi \& Silk, 1983). It tells that if people become well aware with the campaigns through advertising than it could enhance the memory (Loda et al., 2007). 
The more attractive and colorful an advertisement is, the more it is appreciated. Recall for print advertisements appears to be extremely even. Studies of Burke and Rangaswamy (1990) illustrated that the growth of the knowledge based facilitates help identify gaps in perception of the advertising communication process and give the researchers a path for future research (Martínez et al., 2006). Advertisements directly affect the sales of products and it can increase sales of the products (Terill, 2007). Global advertising is the newly introduced phenomenon. Leslie (1995) gave us an idea about it that nowadays advertising agencies have introduced a new concept of "global advertising" to encourage consumers to use one party all over the world and to rationalize their growing dimension and transnational party or organization. Dore and Crouch (2003) also supported the promotional programs, which are watchfully planned gain popularity and are appreciated in addition, promotion relies on how well managed your promotional programs are .

There are three different ways to prompt positive attitude of viewers toward a commercial are: Foremost is to make it compelling so that it seems to be comical. The second is to make it warm, possibly by making the family, children, or associations among friends as the center of attention. The last is to make it personally relevant by relating useful information (Aaker \& Bnizzone, 1981). Moore and Lutz (2000) narrated that products are being promoted through advertising. In addition, children are the ones who are being convinced the most through attractive advertisements; thus resulting in growing buying behaviors towards products. Different forms of illustrative advertising have different meaning and convey different message showing that different forms of advertising can result in different perceptions (Amouzadeh \& Tavangar, 2004). As said before ads have the first impact on consumer's mind and interesting thing is that they also tell us about the quality factor of the product also. Research of Crespi and Marette (2002) explained in their findings that the advertisements have a differential effect on customer's tortuous utilities and his perception about the specific product's quality. Advertising agencies focus on creating such work, which is more convincing and unforgettable for the viewers (Martin, 2008). It shows that advertising could be made more effective with use of such variables, which can increase viewer's memory. This can be created by using different factors like use of innovative designs, music and most prominently colors which is the next component of our research. Giroux (1993) predicted an interesting fact in his research that the advertising and consumption do not contradict politics instead they just redefine it. Advertising can be done in multiple ways but the fact is that it should be attractive and appealing. Advertising; no matter in which way it is done, promotes brands, thus advertising helps in communicating the promotional messages (Bhatia, 2008). World comes to know about the products when it is advertised. People become well aware about different products in microseconds once that product is commercially advertised .

Findings of Buijzen and Valkenburg (2003) showed that advertising affects the way children establish their minds to a product and parents can change their thoughts by telling them their opinion on the advertisement. Thus, we come to know that advertisements influence children and finally parents to buy a particular product. Grow et al. (2006) put forward an interesting phenomenon that, advertisements show how humans are thinking and what actually their minds are. Showing the way humans tend to perceive something. Beside all the importance of advertisement, some researchers and critics contradicted the phenomenon of advertising. As Arrington (1982) in his research took account of critics about advertising, they say that advertising only presents information and in effect let industry grant consumers with what behavior they expect from them.

Colors are some of the core components whenever a marketer or advertisers think of making a new advertisement. Arrington (1982) stated for a Revlon product: "Peach color for Revlon comes "from east of the sun \& west of the moon where each tomorrow dawns" It is "succulent on your lips" and "sizzling on your finger tips (And on your toes, goodness knows)". Let it be your "adventure in paradise". This shows how the colors can be effectively communicated to the end users of the product so that they not only get convinced for a product trail but they should indeed often return to buy it again and again. Colors are selected on the basis of our customers demand and likeness. If our 
targeted segment likes bright colors we will design our packing and advertising in the same frame. Similarly, soft colors will be used for audience preferring soft color scheming. Animations and visuals in the advertisements results in capturing immediate attention of the viewers and hence generate involuntary reactions during the early hours of information processing (Diao \& Sundar, 2004). Different colors have different types of moods allocated to them the way they are perceived. Thus, colors as they are supposed by individuals show individuals repose towards them. Effect of imagining a color was just to strengthen the traces of that color already present in the retinal field (Washburn, 1899). People remember things through the colors they have that's sometimes we listen people saying that: That is just the color of a costume my friend once had and stuff like that (Wolgas, 1962). Every color like red, green, yellow etc. have its own properties depending on their saturation levels and the yellow is less saturated creates a cheerful impact while the same color if highly saturated does not seem cheerful (Andrade \& Egan,1974). Color is one of the major factors influencing the life of product directly or indirectly. Coad and Coad (2008) gave the conclusion of their studies by telling that most admired color preferences are mid blue \& green colors and the 11 years old children and above favored the darkest shades of blues and warm yellow, oranges, pinks, silver and black. This shows the likeness of people regarding the colors of different things. Colors as we perceive them are intrinsic properties of things (Nathan, 1986). As red color symbolizes energy and enthusiasm, so we can say that a product colored red would make the customer think product as lively, original and enjoyable. Selection of colors is a very critical process in the product's marketing strategy according to Samuels and Samuels (1996) and it can help as a cause identifier that's the reason that businesses spend much money to associate their products with a distinguished color to increase its remembrance in the consumer's mind. Two efforts that attempt to generate the idea that competition does not really matter in advertisement but what matters is the actual information contained in the advertisement were (Ridout \& Smith, 2008).

Packaging is another most important factor to be considered while estimating the impact of colors used in packaging of a product on consumers buying behavior. In (2006) Bottomley \& Doyle came to know through their findings that colors associated with the products are considered more suitable for promoting the brand image and thus brand images are perceived according to the colors used they also suggested that users successfully perceive brand images of many multinational companies either functional or sensory social through blue, red colors. A very effective study on consumer beliefs about visuals of a label was done by Bone \& Russo (2001) and the study tells the fact that graphical component of the label can considerably influence characteristic beliefs and buying decisions. This suggests that visuals could be misleading and have an effect on the consumer's buying behavior. The packaging of product influences the buyer to purchase the product. The more attractive the packaging is, the more customer attention it gains. Product itself and its packaging should be done in a way that supports and gives improved livings to the consumers (Nash, 1937). Packaging in effective colors communicates the message product wants to give to it users. The efficient the color scheming is the more it is attractive. Product can be made successful through effective selection of colors in its packaging and other visuals associated with the product. Proper use of visuals can have very positive impact not only on the normal public but also the experts (Mandel \& Johnson, 2002). Therefore, the advertisement, as it affects the buying process needs to be maintained if we want the product sales to be maintained. Mehren (1948) results showed that packaging affects marketing and it has so much effect on consumer response that many packaging firms backed off just because they were not able to meet the standards. Packaging of product works as a silent communicator i.e. the casing of a product attracts the attention of the buyer and helps him decide for the product selection. The first impact of a product on consumer's mind comes from the packaging. The consumer does not use the product in first hand instead makes up his mind for the product. Twedt (1968) supporting the importance of packaging of a product showed that it's the greatest advertising tool. 
Colors in ads and packaging and advertisements have strong impacts on consumers purchase decisions according to a number of researchers. Colors create brand identity and students could easily identify brands through colors scheming (Clayton, 2004). Colors indicate the style followed by a consumer who purchases that product. The results of the study done by North et al. (2003) indicated that style is the most essential trait of clothing to women when making buying decisions, and price is the second most important trait. This shows that style which includes color schemes, designs, and appearance of the product is a very important issue to be considered while planning for a new product. Red and green have different motivation level and behavioral impacts on individuals (Elliot et al., 2009). Today the ads are the things, which hold the young generation's attention toward any new or preexisting product. Biehal et al. (1992) said that ads have the first and direct impact on brand image. White (2001) told that, dress colors show a person's personality and the way he/she looks. Colors tell the state of person's response to life. Colors associated with a particular advertisement or brand will play important roles for the brand itself and thus increases the brand's identification (Gorn et al., 1997). Colors play a vital role in the way we set our minds to an advertisement. No matter how the television has affected people around. The one who are more affected are the children through advertisements. Thus showing that children are affected the most through advertisements and children are motivated toward colors mostly. Dreze and Bell (2003) emphasized on the importance of product design to create a win-win scan-back trade contract, they need close bindings with retailers. It is also observed in daily life experiences that people prefer certain products just for the reason that they look awesome! It shows that product packaging is one of the reasons for its selection. Cox et al. (1997) were the people who studied and showed that eradicating product vulnerability through design and using some type of guarding mechanism to defend users from danger remain the favored technique of protecting product users. Studies done in (1968) by Twedt helps us realize that the consumer perception about the product varies with varying colors used in packaging of that product. Advertisement is an effective tool to communicate things like status, affection, care, fashion, etc., to urban and the rural markets (Aneja, 1996).

Proper use of colors is necessary for the buyers repeat purchase decision as Giles (2002), in his research, explained that unattractive colors are disliked and show a negative attitude towards perception. The perception of our image building revolves around our usage of colors. It is seen that colors play a vital role in selection criteria of a product. It could be exemplify with the concept of boys and girls. Boys prefer blue color whereas girls go for pink shades. Colors have their own meanings and thus image building of anything relies on the color it's associated with in advance to that different end users react differently to different colors (Madden et al., 2000). A known researcher Bittinger (1936) gave details in his study that women are more diverted towards the choice made according to attractive colors. Thus, females selection criteria is based on the way the colors are being used .

This is done so that observation for the product is increased and finally customer attention is achieved. Colors affect the sales of a product and if sellers themselves are dressed in attractive and dazzling colors and in addition their product is also bright in colors, it would certainly attract more buyers (Spek, 2008). Again, the emphasis of blue and white colors used in the country flag provoked a positive impression in the minds of the people (Hynes \& Janson, 2007). Human mind is designed in such a way that people are always attracted towards the beauty and people get motivated if they see bright colors in front of their eyes. Fair (1998) also supported this fact as his studies showed that in clothing purchases people mostly get fascinated with visually instant means of rationalizing these variations in identity. Faber et al. (2004) informed that the information internet provides to consumers will change their brand selection in future. Analysis shows that product is assessed through the way it is being planned. Planning here includes the way the product is presented to the customers and advertised. Thus advertising calculates how our product goes about (Tellis \& Crawford, 1981). Good design, which includes the color and graphics is an important issue (Ives, 1982). On the other hand, Rook and Fisher (1995) said that people who have less impulsive affinity will not follow their buying 
impulse in given situations. While again Anna (2002) supporting the importance of colors said that the thought that colors are less important properties, seems doubtful.

\section{Hypothesis}

H1: There is a positive relationship between the colors used in the advertisements of a product and buying behavior.

H2: There is a positive relationship between the colors used in the packaging of a product and buying behavior.

\section{Research methodology}

Regarding this study, we chose sampling technique for data collection and selected a sample from huge population. Combined with the sampling method, we also used the snowball sampling method. This is a kind of deliberate sample among which the investigator chooses a starting cluster of individuals to whom he/she asks for names of other individuals belonging to the same population. In this way, the sample keeps escalating like a snowball, while new individuals are recommended to the investigator. The sample we selected as our respondents included people ranging from 15 to 55 years of age. Both male \& female respondents were included in the sample.

Collection of primary data for this research paper is through questionnaire and the questionnaires designed for this purpose basically includes three sections. First one is related to buying behavior of consumers for food products, next subdivision is regarding the impact of colors in advertisements and last part is related to the impact of colors in packaging of the food products. In this investigatory study, we selected the option to distribute the questionnaire among the sample population at our own. It can also be said that it was a self administered study. Through the effective command and control of our research team we got 191 responses out of 200 questionnaire distributed among different segments of sample. And all people responded responsibly as we assured them that their views will be kept confidential.

Among all respondents $40.9 \%$ were males and $59.06 \%$ were females. If we see the demographics section, we come to know that $12.75 \%$ of our total respondents were under 20 years of age, $67.78 \%$ were in the age group of $20-26,7.38 \%$ were in the age group of $27-30,7.38 \%$ were in the age group of 31-40 and 5.69\% were over 40 years of age. If we look toward qualification we can observe that $25 \%$ people had an associate's degree $61.48 \%$ had a Bachelor's degree, $6.75 \%$ had a Master's degree and remaining had some other qualifications. TV was the most frequently used media, when looking for information about different products, second most popular media was internet but people also use radio, magazines and newspapers also. 38.51\% of people preferred blue, $10.81 \%$ for red, $12.16 \%$ for purple, $4.72 \%$ for orange, $2.02 \%$ for yellow and 31.75\% preferred other color categories like black, brown and green etc.

\section{Results}

\section{Table 1}

Correlation analysis

\begin{tabular}{lccc}
\hline & BUYING BEHAVIOR & COLORS IN ADS & COLORS IN PACKAGING \\
\hline BUYING BEHAVIOR & 1.000 & $.335^{* *}$ & $.501^{* *}$ \\
COLORS IN ADS & $.335^{* *}$ & 1.000 & $.828^{* *}$ \\
COLORS IN PACKAGING & $.501^{* *}$ & $.828^{* *}$ & 1.000 \\
\hline
\end{tabular}

** Correlation is significant at the 0.01 level (2-tailed). 
Correlation analysis indicates a strong and significant relationship between colors in advertising and buying behavior $\left(0.335^{* *}\right)$. The relationship between the colors in packaging and buying behavior is also very considerable and significant.

Table 2

Regression analysis

\begin{tabular}{llll}
\hline & BETA & $\mathrm{t}$ & SIGNIFICANCE(p) \\
\hline COLORS IN ADS & .711 & 6.407 & .000 \\
\hline COLORS IN PACKAGING & .253 & 2.279 & .024 \\
\hline
\end{tabular}

Dependent Variable: Buying behavior

$\mathrm{n}=191, \mathrm{R} . \mathrm{sqr}=0.272$, Adjusted R.sqr $=0.264$

$\mathrm{F}=35.038$, Significance $=0.00$

The regression analysis indicates value of R.square as 0.272 which means that $27.2 \%$ variation in customers buying behavior for food products is caused by colors used in advertising and packaging. While remaining $72.8 \%$ variation in buying behavior is due to other factors which remained unexplained. The value of $\mathrm{F}$ is 35.038 which are significant at 0.00 . The beta value for colors in ads is 0.711 , and $t$ value is 6.407 which are significant at 0.00 . Similarly the beta value for colors in packaging is 0.253 , and t value is 2.279 which are significant at 0.024 .

\section{Discussion and Conclusion}

This study recommends that a broader range of items and dimensions are relevant in tapping the consumer's attention towards a product. The basis for study is the data used in analysis of results, including the scale for measuring the liking of audience for products according to their color choices. As study suggests that there are many factors, which influence the consumer's choice of a product so only two dimensions are discovered through this study; one is impact of colors in ads and the other is colors in packaging of a product.

Regression analysis done for analyzing the data shows that both of these factors have strong positive impacts on consumer buying behavior. It can be said in the other way also that if products are designed according to the colors choices of its buyers then they will most probably prefer that product if the customer is positively satisfied with other unexplained factors.

We have to accept that every individual has his/her own perception and choice. Packaging and design matter a lot. While choosing a particular product for consumption, our research concluded that colors have great impacts on consumer's buying choice. It is seen that along with the fact that consumers are attracted towards bright and attractive colors of advertising, it is also seen that they have shown positive attitude towards buying a colorfully packed product. Similarly, individuals have their own liking and disliking towards different colors. People from different cultures have different choices of colors and their choices vary on individual basis also. This is one view, if one is not able to select a color on his/her own he/she has to relay on other people in his/her surroundings, either completely or partially. In Pakistan typically our color choices are influenced by our family and friends, they mostly have strong impact on which colors we usually buy. Especially, mothers choose brightly packaged food products for their children as children mostly like primary bright colors in all different things around them. It may include food products, clothing's, toys or anything else.

A person's unique psychological individuality leads to selection of colors in different products. Colors are related to an individual's perception and selection behavior. Different individuals respond differently to different colors. Looking at the Pakistani society we can see that people are attracted more towards primary colors. Their selection and preference are more towards primary colors, which 
are bright and attractively used. Majority of population go for such a product, which is well designed with attractive color scheme. We have collected data from all age groups and it has been concluded that almost all age groups prefer buying products with an attractive packaging and colorful designed advertisement. It is also seen that manufactures are well aware with the consumers mind and mostly products are designed with colorful and attractive primary colors.

If we have to design a packaging for a drink then the packaging should be bright and refreshing. The colors for packaging should be such that consumer is influenced to buy the product. Secondary colors are also seen in our choices that people do not prefer and bright or primary colors are considered as the secondary colors. While designing a product we have to select the proper color schemes. One of the findings of our research showed that colors show perception and feelings of customers associated with the product. We have to be sure that our color scheme of product is matching the product's category and purchasers demand. It means that in every culture there are certain colors associated with certain products specially food products; if companies do not follow those colors in that category of product then their product fails in the market. For example if in Pakistan, a drink is colored blue; no one will accept that color for a drink. Because here in Pakistan certain colors are specified to drinks like red, yellow, orange etc. Advertising is one of the shortest ways to create perception about something without saying something verbally. Colors play a major role in advertising of a product because if an ad is attractive and tempting then a consumer will be automatically influenced by that ad.

We are influenced more by visual appearance of a product, therefore if the color scheming is attractive then the product will be more appealing to eyes of its consumers. Color preferences of our respondents show that red, brown, and orange are the most popular colors associated with food products and blue is preferred in packaging of food colors. Red is often used for advertising and designing of restaurants as we can see in KFC and McDonalds, because it is a refreshing color and is very attractive for customers. Similarly if we see the packaging of certain food products like Olpers, Omore, Nestle, Super Crisps, Walls etc, they all use colors like red, green, blue \& orange in their products as these colors are very attractive for end users and specially children who influence the buying behavior of their parents also as discussed before. Hence, it can be confidently said that attractive colors in advertisements and food packaging throw a positive impact on consumer's mind and his buying behavior.

\section{References}

Aaker, D.A., \& Bnizzone, D.E. (1981).Viewer perceptions of prime-time television advertising. Journal of Advertising research, 5(21), 81-103.

Aaker, D.A., Stayman, D.M., \& Hagerty, M.R.(1986). Warmth in Advertising measurement, Impact, and Sequence Effects. The Journal of Consumer Research, 4(12), 365-381.

Amouzadeh, M., \& Tavangar, M. (2004). Decoding Pictorial Metaphor: Ideologies in Persian Commercial Advertising. International Journal of Cultural studies, 7(2), 147-174.

Aneja,R.H.(1996). Marketing and Selling in India.Economic and Political Weekly,21(31), 26-30.

Anna,G.D.(2002). The Simple View of Colours and the Reference of Perceptual.Philosphy, 299(77), 87-108.

Arrington,R.L.(1982). Advertising and Behavior Control. Journal of Business Ethics, 1(1), 3-12.

Azevedo, S., Pereira, M., Ferreira, J., \& Pedroso, V. (2008). Consumer buying behavior in Fashion Retailing: Empirical Evidences. MPRA,11908(3), 407-411.

Bagozzi, R.P. \& Silk A.J.(1983). Recall, Recognition, and the Measurement of Memory for Print Advertisements. Marketing Science,2(2), 95-134.

Bettman, J.R. (1971). The Structure of Consumer Choice Processes. Journal of Marketing Research, 4(8), 465-471. 
Bhatia,T.J. \& Bhargava, M. (2008). Reaching the Unreachable: Resolving Globalization vs. Localization Paradox. Journal of Creative Communications,3(2), 209-230.

Biehal, G., Stephens, D., \& Curlo, E.(1992). Attitude toward the Ad and Brand Choice. Journal of Advertising, 3(21), 19-36.

Bittinger, C. (1936). Colors Mean More to Women than to Men. The Science News-Letter, 781(29), 204-205.

Bone, P.F. \& France, K.R. (2001). Package Graphics and Consumer Product Beliefs. Journal of Business and Psychology, 3(15), 467-489.

Botterill, J.(2007). Cowboys, Outlaws and Artists: The rhetoric of authenticity and contemporary jeans and sneaker advertisements. Journal of Consumer Culture, 7(1), 105-125.

Bottomley, P.A., \& Doyle, J.R.(2006). The interactive effects of colors and products on perceptions of brand logo appropriateness. Marketing Theory, 6(1), 63-83.

Brody, G.H., Stoneman, S., Lane, T.S., \& Sanders, A.K.(1981). Television Food Commercials Aimed at Children, Family Grocery Shopping, and Mother-Child Interactions. National Council on Family Relations Stable, 3(30), 435-439.

Brown, W.F. (1950). The Determination of Factors Influencing Brand Choice. The Journal of Marketing, 5(14), 699-706.

Buijzen, M., \& Valkenburg, P.M. (2003). The unintended effects of TV advertising: a parent child survey. Communication Research, 5(30), 483-503.

Burke, R.R., Rangaswamy, A., Wind, J., \& Eliashberg, J.(1990). A Knowledge-Based System for Advertising Design. Marketing Science, 3(9), 212-229.

Clayton, R.C.(2004). Designing Brand Identity: A Complete Guide to Creating, Building, and Maintaining Strong Brands. Journal of the Academy of Marketing Science, 3(2), 100.

Coad, J., \& Coad, N.(2008). Children and young people's preference of thematic design and colour for their hospital environment. Journal of Child Health Care, 12(1), 33-48.

Conchar, M. P., Crask, M. R., \& Zinkhan, G. M.(2005). Market Valuation Models of the Effect of Advertising and Promotional Spending: A Review and Meta-Analysis. Journal of the Academy of Marketing Science, 4(33), 445-460.

Cox III, E.P., Wogalter, M.S., Stokes, S.L., \& Murff, E.J.T.(1997). Do Product Warnings Increase Safe Behavior? A Meta-Analysis. Journal of Public Policy \& Marketing, 2(16), 195-204.

Crespi, J.M., \& Marette, S.(2002). Generic Advertising and Product Differentiation. American Journal of Agricultural Economics,3(84), 691-701.

D'Andrade, R., \& Egan, M. (1974). The Colors of Emotion. American Ethnologist, 1(1), 49-63.

Diao, F., \& Sundar, S.S.(2004). Orienting Response and Memory for Web Advertisements: Exploring Effects of Pop-Up Window and Animation. Communication research, 5(31), 537-567.

Dijck, J.V. (2008). Digital photography: communication, identity, memory. Visual Communication,7(1), 57-76.

Dore, L., \& Crouch, G.I.(2002). Promoting destinations: An exploratory study of publicity programs used by national tourism organizations. Journal of Vacation Marketing, 2(9), 137-151.

Drèze, X., \& Bell, D.R.(2003). Creating Win-Win Trade Promotions: Theory and Empirical Analysis of Scan-Back Trade Deals. Marketing Science, 1(22), 16-39.

Elliot, A.J.E, Maier, M.A., Binser, M.J., Friedman, R.\& Pekrun, R.(2009). The Effect of Red on Avoidance Behavior in Achievement Contexts. Personality and Social Psychology Bulletin, 3(5), 365.

Faber, R.J., Lee, M.,\& Nan, X.(2004). Advertising and the consumer information environment online. American Behavioral Scientist,4(48), 447-466.

Fair, L. (1998). Dressing up: Clothing, Class and Gender in Post-Abolition Zanzibar. The Journal of African History, 1(39), 63-94.

Friedmann, R., \& Zimmer, M.R. (1988). The Role of Psychological Meaning in Advertising. Journal of Advertising, 1(17), 31-40.

Gardner, B.B., \& Cohen,Y.A. (1964). ROP Color and Its Effect on Newspaper Advertising. Journal of Marketing Research, 2(1), 68-70. 
Gardner, M.P. (1985). Mood States and Consumer Behavior: A Critical Review. The Journal of Consumer Research, 3(12).

Giles, D. (2002). Keeping the public in their place: audience participation in lifestyle television programming. Discourse \& Society, 13(5), 603-628.

Giroux, H.A.(1993-1994). The United Colors of Benetton. Cultural Critique, 26, 5-32.

Gorn, G.J. (1982). The Effects of Music in Advertising on Choice Behavior: A Classical Conditioning Approach. The Journal of Marketing, 1(46), 94-101.

Gorn, G.J., Chattopadhyay, A., Yi, T., \& Dahl, D.W.(1997). Effects of Color as an Executional Cue in Advertising: They're in the Shade. Management Science, 10(43), 1387-1400.

Gronhaug, K.(1976). Exploring Environmental Influences in Organizational Buying. Journal of Marketing Research, 3(13), 225-229.

Grow, J.M., Park, J.S., \& Han, X.(2006). "Your Life is Waiting!": Symbolic Meanings in Direct-toConsumer Antidepressant Advertising. Journal of Communication Inquiry, 2(30), 163-188.

Hempel, D.J.(1974). Family Buying Decisions: A Cross-Cultural Perspective. Journal of Marketing Research, 3(11), 295-302.

Hynes, G.H., \& Janson, M. (2007). Global Imagery in Online Advertisements. Business Communication Quarterly, 70(4), 487-492.

Ives, B. (1982). Graphical User Interfaces for Business Information Systems. Management Information Systems Research Center, 6, 15-47.

Kacen, J.J., \& Lee, J.A. (2002). The Influence of Culture on Consumer Impulsive Buying Behavior. Journal of Consumer Psychology, 2(12), 163-176.

Leslie, D.A. (1995). The globalization of advertising agencies, concepts, and campaigns. Economic Geography, 4(71), 402-426.

Leurdijk, A. (2006). In search of common ground: Strategies of multicultural television producers in Europe. European Journal of Cultural studies, 9(1), 25-46.

Loda, M.D., Norman,W., \& Backman, K.F. (2007). Advertising and publicity: Suggested new applications for tourism marketers. Journal of Travel Research, 45, 259-265.

Lotz, A.D. (2007). How to spend $\$ 9.3$ billion in three days: examining the upfront buying process in the production of US television culture. Media, Culture \& Society, 29(4), 549-567.

Madden, T.J., Hewett, K., \& Roth, M.S.(2000). Managing Images in Different Cultures: A CrossNational Study of Color Meanings and Preferences. Journal of International Marketing, 4(8), 90107.

Mandel, N., \& Johnson, E.J. (2002). When Web Pages Influence Choice: Effects of Visual Primes on Experts and Novices. The Journal of Consumer Research, 2(29),235-245.

Martin, E. (2008). Language-Mixing in French Print Advertising. Journal of Creative Communications, 1(3), 49-76.

Martínez, I.J.M., Prieto, M.D., \& Farfán, J. (2006). Childhood and violence in advertising. International Communication Gazette, 68(3), 269-287.

Mehren, G.L. (1948). Consumer Packaging of Fruits and Vegetables in California. The Journal of Marketing, 3(12), 327-336.

Moore, E.S., \& Lutz, R.J.(2000). Children, Advertising, and Product Experiences: A Multimethod Inquiry. The Journal of Consumer Research, 1(27), 31-48.

Nash, B.(1937). Product Development. The Journal of Marketing, 3(1), 254-262.

Nathan, N.(1986). Simple Colors. Royal Institute of Philosophy, 237(61), 345-353.

North, E.J., Vos, R.B.D., \& Kotzé, T.(2003). The importance of apparel product attributes for female buyers. Journal of Family Ecology and Consumer Sciences, 31,41-51.

O'Guinn, T.C., \& Faber, R.J.(1989). A Phenomenological Exploration. The Journal of Consumer Research, 2(16), 147-157.

Oropesa, R.S.(1995). Consumer Passions, and Subjective Well-Being. Sociological Forum, 2(10).

Padberg, D.S., \& Westgren, R.E.(1979). Product Competition and Consumer Behavior in the Food Industries. American Journal of Agricultural Economics, 4(61), 620-625. 
Palmeri, T.J., Blake, R., Marois, R.M., Flanery, M.A., \& Jr,W.W. (2002). The Perceptual Reality of Synesthetic Colors. Proceedings of the National Academy of Sciences of the United States of America, 6(99), 4127-4131.

Ridout,T.N., \& Smith, G.R. (2008). Free advertising: how the media amplify campaign messages. Political Research Quarterly, 4(61), 598-608.

Rook, D.W., \& Fisher, R.J.(1995). Normative Influences on Impulsive Buying Behavior. The Journal of Consumer Research, 3(22), 305-313.

Samuels, L.B., \& Samuels, J.M.(1996). Color Trademarks: Protection under U.S. Law. Journal of Public Policy \& Marketing, 2(15), 303-307.

Sewall, M.A.(1978). Market Segmentation Based on Consumer Ratings of Proposed Product Designs. Journal of Marketing Research, 4(15). 557-564.

Spek, K.V.D. (2008). Faked antikas and 'modern antiques': The production and marketing of tourist art in the Theban Necropolis. Journal of Social Archaeology, 8(2), 163-189.

Stern, H.(1962). The Significance of Impulse Buying Today. The Journal of Marketing, 2(26), 59-62.

Tellis, G.J.,\& Crawford, C.M. (1981). An Evolutionary Approach to Product Growth Theory. The Journal of Marketing, 4(45), 125-132.

Timmermans, H., Heyden, R.V.D., \& Westerveld,H.(1984). Decision-Making Experiments and RealWorld Choice Behavior, Geografiska Annaler. Series B, Human Geography, 1(66), 39-48.

Twedt,D.W.(1968). How Much Value Can Be Added Through Packaging? The Journal of Marketing, 1(32), 58-61.

Washburn, M.F.(1899). Subjective Colors and the After-Image: Their Significance for the Theory of Attention. Mind, New Series, 29(8), 25-34.

White, A.G.(2001). NO RULES, ONLY CHOICES? Repositioning the Self within the Fashion System in Relation to Expertise and Meaning: A Case Study of Color and Image Consultancy. Journal of Material Culture, 6(2), 193-211.

Wolgas, E.H.(1962). A Question about Colors. The Philosophical Review, 3(71), 3 28-339.

Young, T.(1802). An Account of Some Cases of the Production of Colors, not hitherto Described. Transactions of the Royal Society of London, 92, 387-397. 